\title{
OPTIMUM WINDOW POSITION IN THE BUILDING FAÇADE FOR HIGH DAY-LIGHT PERFORMANCE: EMPIRICAL STUDY IN HOT AND DRY CLIMATE
}

\author{
${ }^{1}$ Messaouda RAIS ${ }^{*},{ }^{2}$ Sara ELHADAD,${ }^{3}$ Adel BOUMERZOUG \\ ${ }^{4}$ Bálint BARANYAI \\ ${ }^{1}$ Marcel Breuer Doctoral School, Department of Building Structures and Energy Design \\ Institute of Architecture, Faculty of Engineering and Information Technology \\ University of Pécs, Boszorkány u. 2, H-7624 Pécs, Hungary \\ e-mail: messaouda.raiss@gmail.com \\ ${ }^{2}$ Marcel Breuer Doctoral School, Department of Building Structures and Energy Design \\ Institute of Architecture, Faculty of Engineering and Information Technology \\ University of Pécs, Boszorkány u. 2, H-7624 Pécs, Hungary \\ and Department of Architecture, Faculty of Engineering, Minia University \\ 6111 Minia, Egypt, e-mail: sarareda@mu.edu.eg \\ ${ }^{3}$ Institute of Architecture, University Mohamed Khider Biskra, BP 145 RP, 07000 \\ Biskra, Algeria, e-mail: boumerzoug.adel@hotmail.com \\ ${ }^{4}$ Department of Building Structures and Energy Design, Institute of Architecture \\ Faculty of Engineering and Information Technology, Boszorkány u. 2 \\ and János Szentágothai Research Center, Ifjúság u. 20, University of Pécs \\ H-7624 Pécs, Hungary, e-mail: balint.baranyai@mik.pte.hu
}

Received 18 December 2019; accepted 5 February 2020

\begin{abstract}
Day-lighting studies in buildings play a major role in indoor environmental investigation and can be conducted at the early stages of building design. Window position significantly affects day-lighting performance. This paper assessed the impacts of the window position on the visual comfort through two main factors; daylight factor and light uniformity in the hot and dry climate zone. In this study different window positions have been examined to achieve optimal visual comfort, using a dynamic simulation through Vi-suit plugin for Blender $3 \mathrm{D}$ software that controls the external application Radiance software. The results revealed that the window position at sill start from $1.4 \mathrm{~m}$ of a room characterized by $(4.30 \mathrm{~m} \times 3.00 \mathrm{~m} \times 3.00 \mathrm{~m})$ is the best compromising solution that complies with the daylight factor and light uniformity standards in the indoor environment. The findings of this study provide a more detailed and comprehensive analysis of the window design for architects/designers in the early building design stages in the hot and dry climate region.
\end{abstract}

Keywords: Visual comfort, Window position, Light uniformity, Daylight factor

${ }^{*}$ Corresponding Author 


\section{Introduction}

Buildings are the largest consumer, attributing approximately $40 \%$ of the world's energy consumption. Large energy consumption of buildings is accounted for heating, cooling, and lighting [1]. In residential buildings, cooling is the largest energy consumer in a hot and dry climate, while lighting is the active energy consumption in commercial buildings in the US [2]-[4]. However, most of the building's electricity is generated from fossil fuels. Using these energy resources has caused many environmental problems like climate change and global warming [5]. Many previous studies reported that maximizing the use of natural lighting levels led to a significant reduction in electricity consumption. Moreover, day-lighting represents one of the passive strategies that contribute to a more sustainable design approach and allows users to take advantage of the energy-saving opportunity through daylight dimming and other integrated control strategies [6]-[8]. In addition, energy energy-efficient in daylight reduces harmful environmental impacts by reducing the use and need for power plants [9]. Furthermore, to ensure best practices in comfort and visual performance for building occupants with less energy consumption, visual comfort related to high daylight performance should be considered at the design stage [10].

Currently, façade design has become an important part of the environmentally friendly building's design [11]. Windows configurations in the building façade distinguish the energy use and visual comfort patterns in buildings; they provide an internal environment for lighting transmission and allow visual communication with outdoors-for the occupants of the building [12]. Several studies have been conducted on the design of energy-efficient buildings. In this regard, the windows have a significant impact on the total energy consumption as they are responsible for $28 \%$ and $18 \%$ of reduction on heating and cooling demand respectively, and $26 \%$ of reduction on the daylight performance if a triple-pane glass is integrated into the window [13]. Furthermore, the choice of areas and proportions is a part of the basic decisions of the early design phase, which is difficult to change later. Moreover, the window position has to be selected from a precise procedure and has to be a part of an integrated design procedure, considering multiple aspects at the same time. Many studies have been conducted to study the impact of window design on energy load and daylighting performance considering different window factors. In addition, the size, direction, and position of the windows are the main parameters affecting daylight performance and visual comfort, besides the energetically impact [14]-[15].

Otherwise, the provision of a comfortable indoor environment is one of the required design principle that has to be met by buildings, the assessment parameters of visual comfort generally depend on the daylight factor $(D F \%)$, the light uniformity, the glare control and view out. The Building Research Establishment Environmental Assessment Method (BREEAM), is one of a widely used method and tool that has defined the standards, which can provide visual comfort for the indoor environment [16]. This establishment has expanded from individual new dwellings at the construction stage to include the whole life cycle of dwellings from planning to refurbishment and in-use. The ongoing need to enhance sustainability, feedback to respond from industry and support the UK's sustainability commitments and strategies drove the regular updates and revisions of BREEAM [17]. 
As building design is becoming more dynamic and complex in a severe climate of the hot and dry regions, the design of the openings, which is the main source of the heat gain, becomes more complex to provide visual comfort and thermal comfort with less energy consumption. A more detailed and comprehensive analysis of the different design factors for windows is required. At this end, this empirical study applied in hot and dry climate zone, it is focused on evaluating the effects of window position in the building façade on the daylight performance, assessing in interaction two main visual comfort factors; the light uniformity and the daylight factor.

\section{Methods}

The objective of this study is to assess the impact of the window's vertical position on visual comfort in a hot and dry climate. An empirical methodology has been used to fulfill this aim through a lighting simulation using Vi-suite add on Blender 3D software that controls the external application radiance [18]. The virtual room of $(3.00 \mathrm{~m} \times 3.00$ $\mathrm{m} \times 4.30 \mathrm{~m}$ ) was molded, and Window size to Wall Ratio (WWR) of $25 \%$ was selected, see Fig. 1. The context is focused on the city of Biskra, located in north-eastern of Algeria on the northern edge of the Sahara Desert at the latitude of $34^{\circ} 48^{\prime}$ north and a longitude of $5^{\circ} 44^{\prime}$ east. It rises to an altitude of 86 meters.

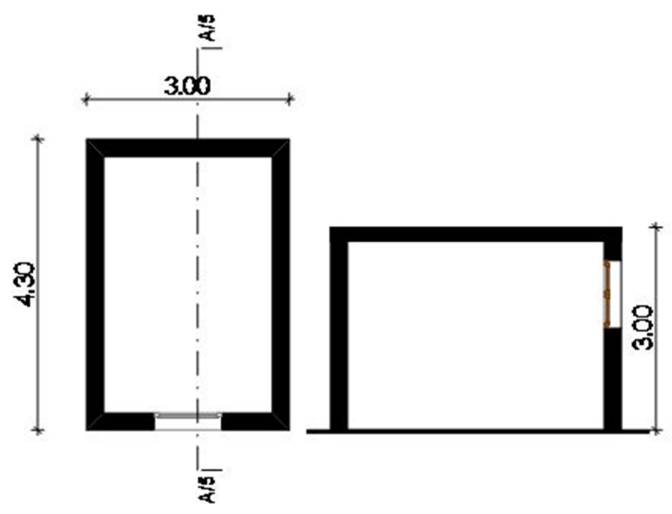

Fig. 1. The simulated virtual model

Fifteen different window position scenarios have been established. The distance from the windowsill was switched from $0.85 \mathrm{~m}$ to $1.55 \mathrm{~m}$, adding $5 \mathrm{~cm}$ for each scenario. The window was assumed to be installed on the south-facing wall in this experiment. This is due to the fact that south-oriented spaces are able to exploit daylight and benefit from the direct solar gains in the winter and prevent the solar heat gain in the summer with a simple solar control device. In addition, this orientation is required for the hot and dry climate regions to be a dominated façade in the building design [19].

The BREEAM has been used as a standard reference in this study to find the optimal solution that complies with the visual comfort requirements Fig. 2. 


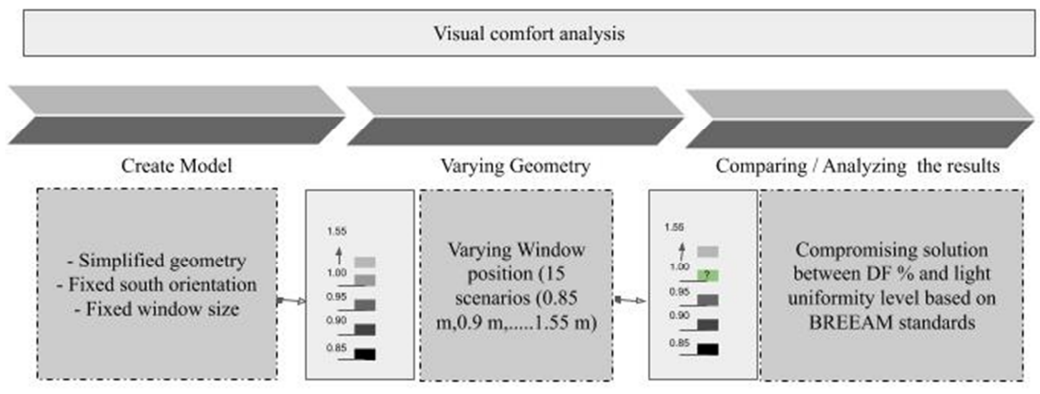

Fig. 2. Empirical methodology process for analyzing the daylight factor and the light uniformity

Two main factors have been used to assess the visual comfort performance, as it is described in [17]. The daylight factor $(D F \%)$, which is a percentage ratio between the interior illuminance level $(E i)$ of horizontal work plane $(0.85 \mathrm{~m})$ and the external illuminance $(E o)$ during cloudy sky conditions, see Eq. (1),

$$
D F=\frac{E i}{E O} 100 \%
$$

In addition, an average value of $2 \%$ is required for more than $80 \%$ of the floor area as is defended by the BREEAM standard.

The second factor is the uniformity of light, which is usually defined as the ratio of the minimal illuminance over the area-weighted average illuminance, see Eq. (2),

$$
U=\frac{E_{\min }}{E_{\text {Aeverage }}} .
$$

The minimum illuminance should correspond to the recommended illuminance as it is defined in the national codes of practice. The optimum value 0.3 of the uniformity ratio is determined in the BREEAM standards, as well as in the calculation process areas within $0.5 \mathrm{~m}$ of the walls can be not regarded as part of the working plane for this purpose. However, in this study, these areas were included to calculate the uniformity ratio.

\section{Results and discussion}

\subsection{Average daylight factor analysis}

In this study, the average daylight factor is assessed in 4 design days in the whole year (21 December, 21 March, 21 June, and 21 September). The maximum value of the average daylight factor reached $7.8 \%$ in June, while the minimum value was $3.9 \%$ in 
December. Simultaneously in March and September, the average daylight factor rates were approximately the same (from $6 \%$ to $6.4 \%$ ). All the values are conforming according to the BREEAM standard, which indicates that the average daylight factor should be more than $2 \%$ in living rooms. The window position variation shows a significant impact on the average daylight factor; the maximum value of this factor was reached while the windowsill height was $1.1 \mathrm{~m}$ for all the design days. Fig. 3 shows the variation of the daylight factors in relation to the window position.

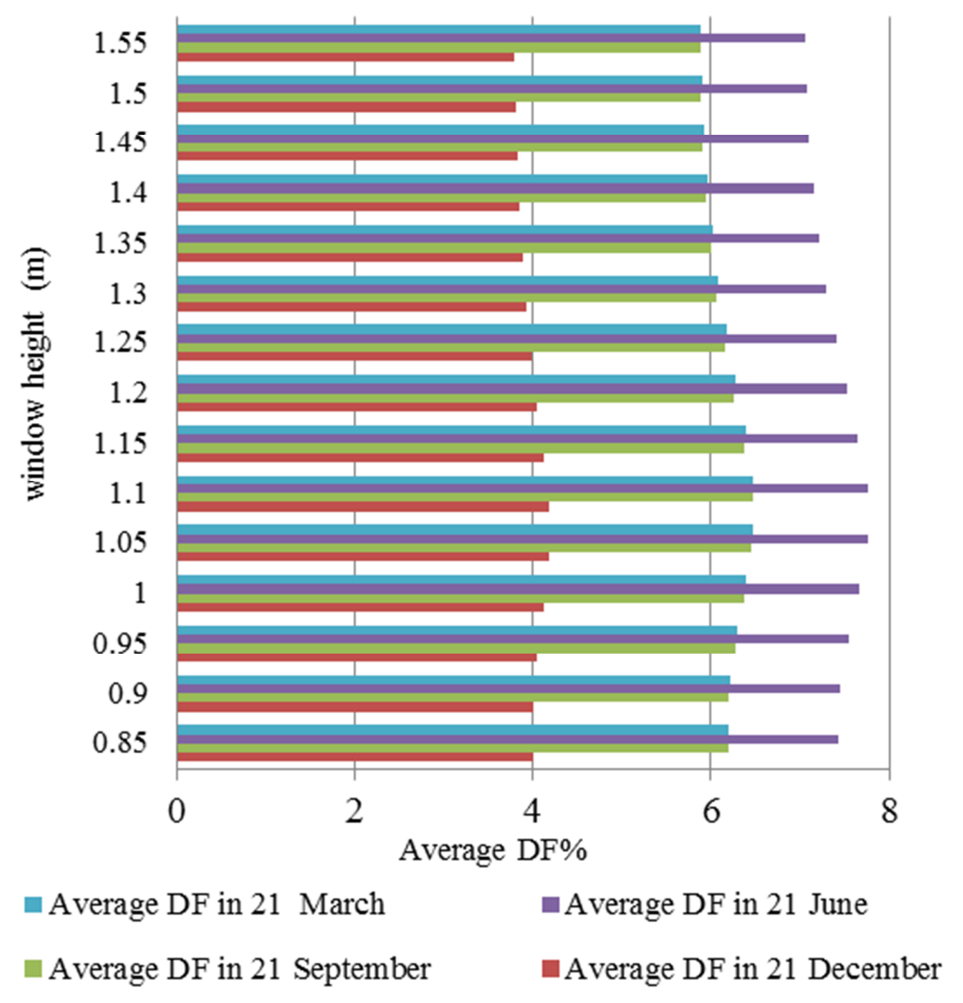

Fig. 3. Average daylight factor for the different scenarios in 4 design days in the year

\subsection{Compliance area of the required daylight factor}

In order to analyze the compliance area with the required daylight factor according to the BREEAM standard, a comparison between the different scenarios in the different design days has been performed. The results show that for all the design days the percentage of areas that comply with $2 \%$ of the $D F$ in more than $80 \%$ of the total room area is increasing as soon as the windowsill becomes more elevated. In December none of the window positions are compliant with BREEAM Standard, the minimum value is $52 \%$ for a windowsill of $0.85 \mathrm{~m}$ and the maximum value $65 \%$ for a windowsill $1.50 \mathrm{~m}$. 
Moreover, in September and March, the values are approximately the same; the minimum value is $66 \%$ for a windowsill $0.85 \mathrm{~m}$ and the maximum value $93 \%$ for a windowsill $1.55 \mathrm{~m}$. The compliance with the BREEAM standard starts when the windowsill is above $1.23 \mathrm{~m}$. Furthermore, on 21 June the minimum value is $74 \%$ for a windowsill $0.85 \mathrm{~m}$, and the required value is reached when the windowsill is above $1.08 \mathrm{~m}$, and the maximum value becomes $100 \%$ starting from $1.4 \mathrm{~m}$ of a windowsill.

These results revealed that a windowsill of $1.23 \mathrm{~m}$ is required to provide an average value $2 \%$ of the daylight factor for more than $80 \%$ of the floor area, for September June and March, while the winter (December) require more daylighting strategies if the window to wall ratio is $25 \%$ as it has experimented in this study Fig. 4.

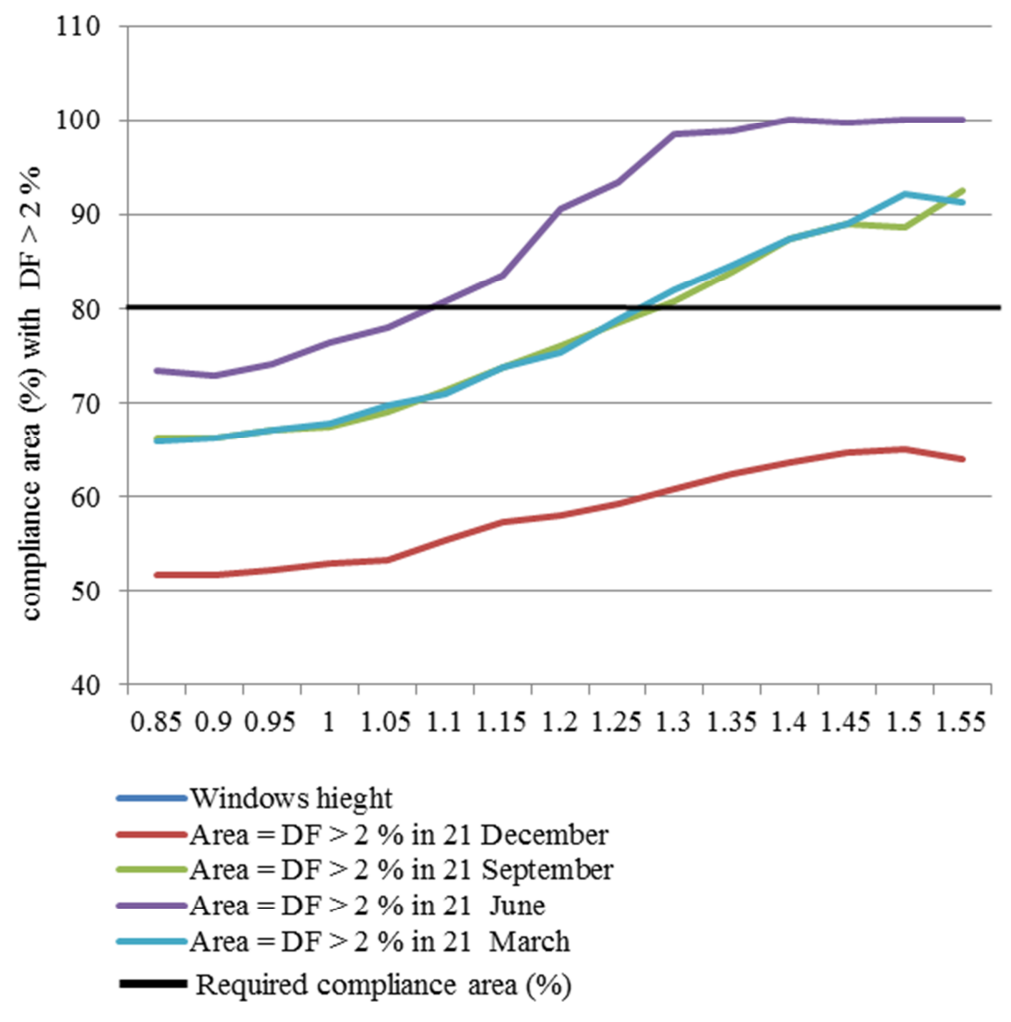

Fig. 4. The distribution compliance with the average value of $2 \%$ of $D F$ in the floor area

\subsection{Daylighting uniformity analysis}

In this research, the result of the light uniformity simulation shows a variation depending on design days and the window position. The uniformity ratio is increasing as soon as the windowsill becomes more elevated. 
The lowest light uniformity ratio of 0.16 is attained through a windowsill height of $0.9 \mathrm{~m}$. However, the maximum ratio of the light uniformity is reached 0.29 when the windowsill is $1.5 \mathrm{~m}$. This window sill position $(1.5 \mathrm{~m})$ provides approximately the required uniformity level (0.3) of the BREEAM standard, Fig. 5.

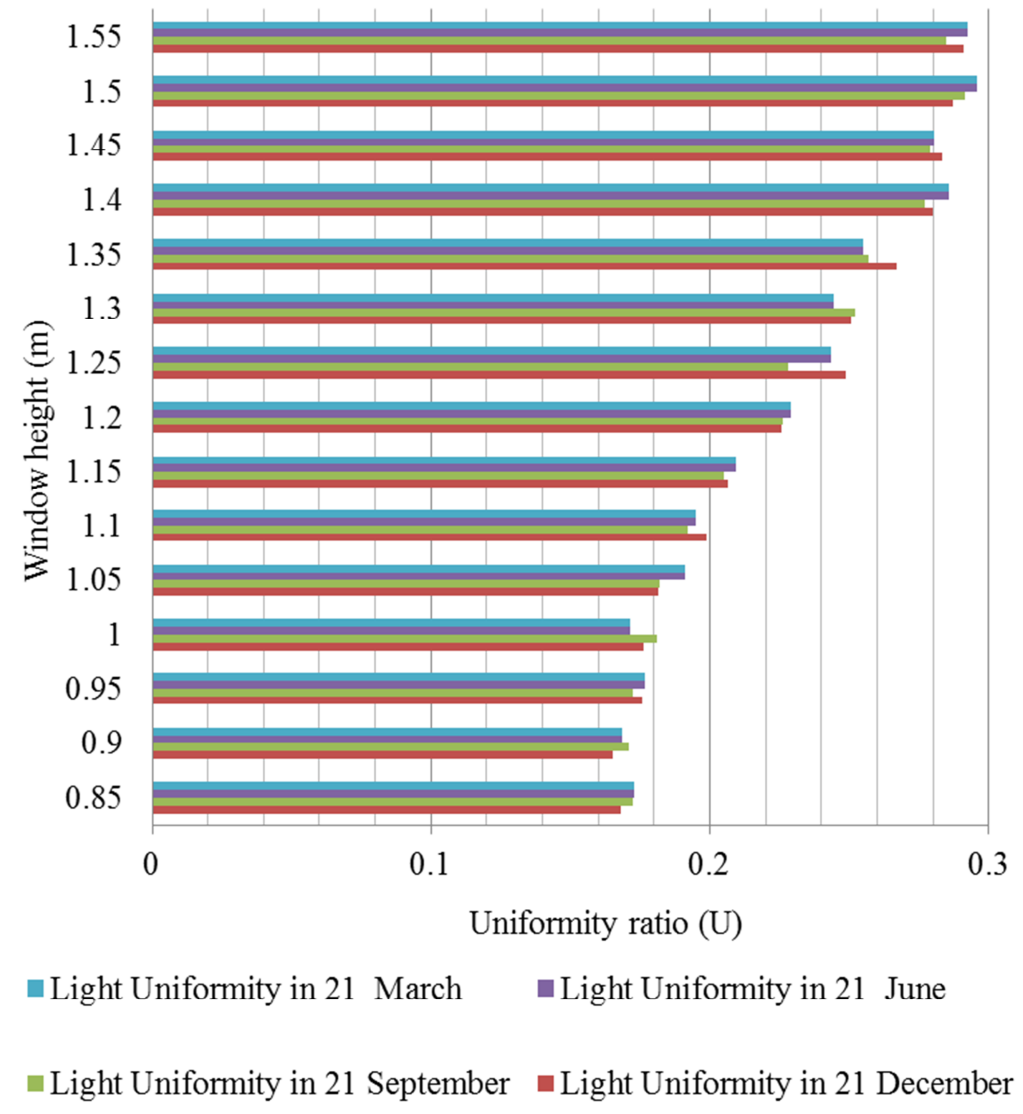

Fig. 5. Daylighting uniformity ratio for the different scenarios in the different design days

\subsection{Analyzing the compromising position}

The analysis of the daylighting uniformity ratio and the daylight factor and area compliance shows a certain opposition related to the results. For the average daylight factor, the maximum values are between $(0.9 \mathrm{~m}$ and $1.2 \mathrm{~m})$ of a windowsill elevation. While, in the light uniformity and the compliance area with the required $D F \%$ started when the windowsill is $1.23 \mathrm{~m}$ for the three design days (March, June, and September). However, the best light uniformity rates are attained as the windowsill was between 1.4 $\mathrm{m}$ to $1.55 \mathrm{~m}$, Fig. 6 . 

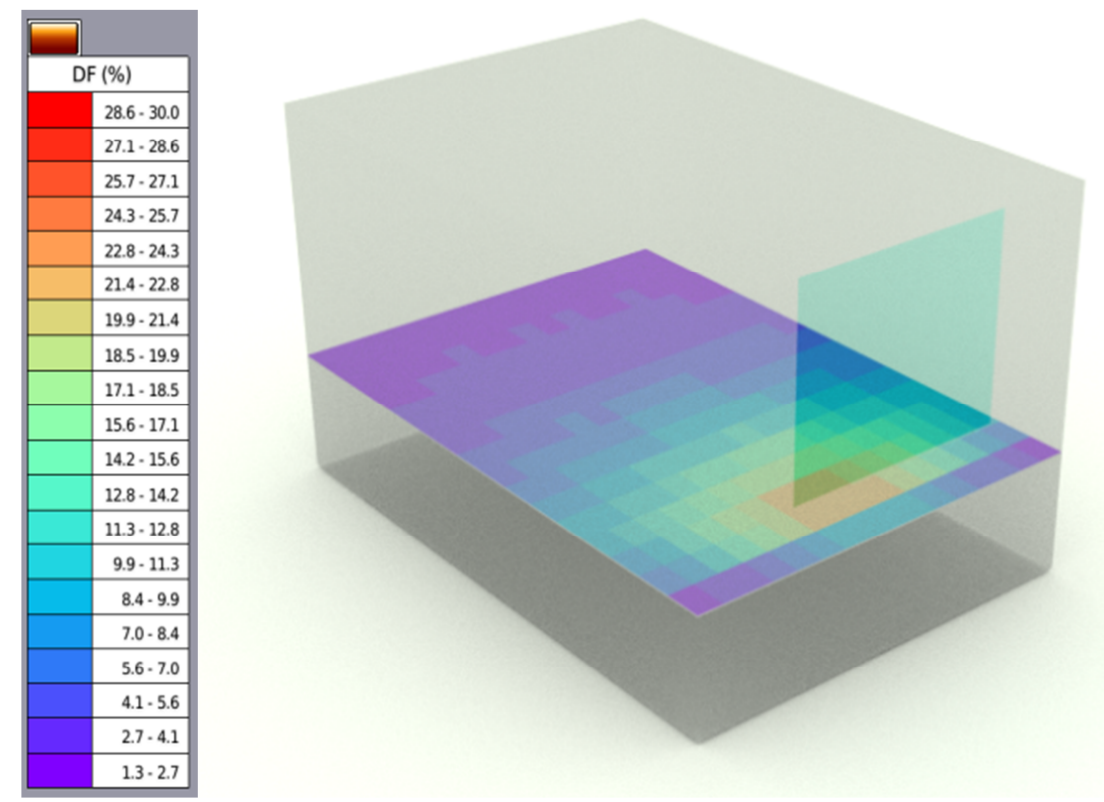

Fig. 6. The best day-lighting uniformity results 21 June at 12:40 windows position $1.5 \mathrm{~m}$

\section{Conclusion}

Maintaining visual comfort artificially is one of the parameters that influence the amount of energy consumption in buildings. This aspect is related to the window configuration in the building façade, which is the main interest of the present paper. The study applied an empirical methodology using the plugin Vi-suit that uses Blender 3D software to control the external application radiance; it is performed in a hot and dry climate zone.

The study results revealed that the vertical window position has a significant impact on the visual comfort of the indoor environment. By the assessment of the daylight factor and daylight distribution and the light uniformity, it was concluded that these factors should be analyzed in the interaction method during the early design stage of design. Moreover, in this study, the light uniformity has a priority than the daylight factor to determine the optimal window position, which was in the highest level of the windowsill. In this experimental research, it was found, the optimal windowsill starts from $1.4 \mathrm{~m}$ to the highest rate when the window to wall ratio is $25 \%$, and the room dimensions are $(4.30 \mathrm{~m} \times 3.00 \mathrm{~m} \times 3.00 \mathrm{~m})$, regarding a window facing south orientation. In addition, daylighting design strategies (light shelves, skylight, etc.) are required in the winter period in order to reach optimum daylight performance.

Finally, as the brightness of the sky depends mainly on the sun position, the daylight amount can vary in each orientation. Consequently, the methodology used can be applied to the study of any building type for other orientations, regarding not only the visual comfort but the cooling/heating demand as well. 


\section{Acknowledgments}

The present scientific contribution is dedicated to the $650^{\text {th }}$ anniversary of the foundation of the University of Pécs, Hungary. The Authors would like to thank Dr. Ryan Southall researcher and developer of VI-suite of Blender 3D code, University of Brighton, School of Architecture and Design, for his help and great support.

In addition, the second author would like to thank the Egyptian Ministry of Higher Education and Tempus Public Foundation for providing him/her the Stipendium Hungaricum Scholarship.

\section{Open Access statement}

This is an open-access article distributed under the terms of the Creative Commons Attribution 4.0 International License (https://creativecommons.org/licenses/by/4.0/), which permits unrestricted use, distribution, and reproduction in any medium, provided the original author and source are credited, a link to the CC License is provided, and changes - if any - are indicated. (SID_1)

\section{References}

[1] William S., Aerschot C., Kornevall C., Cowe R., Bridoux D., Bonnaire T. B., Fritz, J. Energy efficiency in buildings: Transforming the market, Switzerland, World Business Council for Sustainable Development (WBCSD), 2009.

[2] Elhadad S., Baranyai B., Gyergyak J. The impact of building orientation on energy performance: A case study in New Minia, Egypt, Pollack Periodica, Vol. 13, No. 3, 2018, pp. $31-40$.

[3] Elhadad S., Rais M., Boumerzoug A., Baranyai B. Assessing the impact of local climate on the building energy design: Case study Algeria-Egypt in hot and dry regions, Proceeding of 172nd International Conference on Science, Engineering and Technology, Istanbul, Turkey, 20- 21 November 2019, pp. 21-24.

[4] Sawyer K. (Ed.) Windows and building envelope research and development, Roadmap for emerging technologies, US Department of Energy, Office of Energy Efficiency and Renewable Energy, 2014.

[5] Shafiee S., Topal E. An econometrics view of worldwide fossil fuel consumption and the role of US, Energy Policy, Vol. 36, No. 2, 2008, pp. 775-86.

[6] Ihm P., Nemri A., Krarti M. Estimation of lighting energy savings from daylighting, Building and Environment, Vol. 44, No. 3, 2009, pp. 509-514.

[7] Singh M. C., Garg S. N. Illuminance estimation and daylighting energy savings for Indian regions, Renewable Energy, Vol. 35, No. 3, 2010, pp. 703-711.

[8] Yu X., Su Y. Daylight availability assessment and its potential energy saving estimation A literature review, Renewable and Sustainable Energy Reviews, Vol. 52, 2015, pp. 494-503.

[9] David J., Newborough M. An approach for estimating the carbon emissions associated with office lighting with a daylight contribution, Applied Energy, Vol. 84, No. 6, 2007, pp. 608-622.

[10] Hausladen G., De Saldanha M., Liedl P. ClimateSkin: Building-skin concepts that can do more with less energy, Birkhauser, 2008. 
[11] Rais M., Boumerzoug A., Halada M., Leila S. Optimizing the cooling energy consumption by the passive traditional façade strategies in hot dry climate, Pollack Periodica, Vol. 14, No. 1, 2019, pp. 177-188.

[12] Newsham G., Brand J., Donnelly C., Veitch J., Aries M., Charles K. Linking indoor environment conditions to job satisfaction: a field study, Building Research and Information, Vol. 37, No. 2, 2009, pp. 129-147.

[13] Elhadad S., Baranyai B., Gyergyak J., Kistelegdi I., Salem A. Passive design strategies for residential buildings in the hot desert climate in Upper Egypt, XXth International Multidisciplinary Scientific Geo-Conference on Surveying, Geology and Mining Ecology and Mangement, Albena Resort \& Spa, Bulgaria, 27 June - 6 July 2020, Vol. 19, 2019, pp. 495-502.

[14] Bokel R. M. J. The effect of window position and window size on the energy demand for heating, cooling and electric lighting, Proceedings: Building Simulation Vol. 10, 2007, pp. 117-121.

[15] Koohsari A. M., Fayaz R., Kari B. M. The influence of window dimensions and location on residential building energy consumption by integrating thermal and lighting analysis in a mild and humid climate, MAGNT Research Report, Vol. 3, No. 4, 2015, pp. 187-194.

[16] Giarma C., Tsikaloudaki K., Aravantinos D. Daylighting and visual comfort in buildings' environmental performance assessment tools: A critical review, Procedia Environmental Sciences, Vol. 38, 2017, pp. 522-529.

[17] BREEAM New Construction Technical Standard, Non domestic buildings, UK Technical Manual 2014, Reference: SD5076, Issue: 4.1, (last visited 11 November 2019).

[18] Southall R., Biljecki F. The VI-Suite: A set of environmental analysis tools with geospatial data applications, Open Geospatial Data, Software and Standards, Vol. 2, No. 23, 2017, pages 13.

[19] Berghout B. Effect of the implementation of collective building on interior hydrothermal comfort: case of Biskra, Algeria, (in French) MSc Thesis, School of Higher Technology, University of Quebec, 2012. 